antibody method is used and the stages are as follows:

1 Slides are fixed in Baker's formol-calcium for $4 \mathrm{~min}$ and washed in phosphatebuffered saline (PBS).

2 Monoclonal antibody $(15 \mu \mathrm{l})$ is applied to a $5 \mathrm{~mm}$ area, and the slides are left at room temperature in a humid chamber for $30 \mathrm{~min}$.

3 They are washed in four changes of PBS over a period of $20 \mathrm{~min}$.

4 Fluorescein isothiocyanate-labelled goat antimouse IgG (15 $\mu \mathrm{l})$ (Meloy Laboratories) is applied and incubated as before for $30 \mathrm{~min}$. A duplicate slide, to which primary antiserum has not been applied, is similarly treated.

5 Washing is repeated as in stage 3.

6 Slides are mounted in Bacto FA mounting fluid $\mathrm{pH} \mathrm{7.2} \mathrm{(Difco)} \mathrm{and} \mathrm{sealed} \mathrm{with}$ Glyceel (Searle Diagnostic).

The preparations are examined immediately using either a Leitz Ortholux I microscope with $200 \mathrm{~W}$ mercury lamp or a Leitz Ortholux II with $50 \mathrm{~W}$ mercury lamp, or can be stored at $+4^{\circ} \mathrm{C}$ for a considerable length of time, at least two weeks, before examination.

\section{Results and comment}

Examples of our results are shown in Figures (a) and (b). A ring-like pattern of fluorescence is obtained at this magnification. Figure (a) is an OKT8reacted cytospin of peripheral blood lymphoid cells from a known case of $T$ prolymphocytic leukaemia of supressor type, whose lymphocytes had been kept in liquid nitrogen after her demise in 1979. Live cell staining showed $58 \%$ of cells to be positive with OKT 8 while only $2.5 \%$ of cells were positive with OKT4. Figure (b) is an OKT8-reacted imprint from a lymph node "replaced" by a diffuse lymphocytic lymphoma of $\mathbf{M \kappa}$ immunoglobulin type showing positive supressor $T$ cells scattered through the negative larger lymphoma cells.

We have found this method satisfactory with the following antibodies: OKT3, OKT4, OKT6, OKT8, OKIal (Ortho Diagnostic Systems) and with anti J5 or CALLA which detects the common acute lymphoblastic leukaemia antigen (Coulter Clone). It is easy and quick to perform and the results are rapidly and reliably interpretable. In addition to its diagnostic advantages, the use of this method allows a panel of slides to be kept at $-70^{\circ} \mathrm{C}$ and therefore readily available for control of future tests.

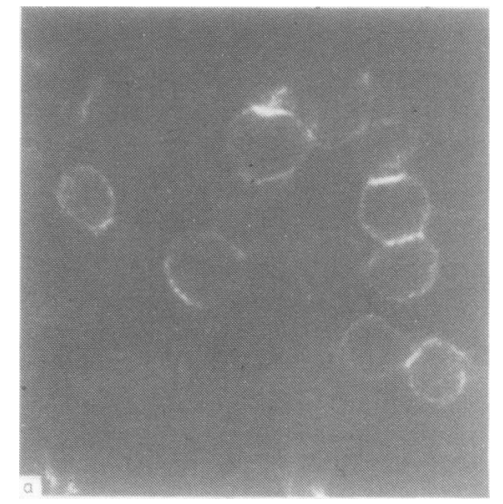

(a) OKT8 reacted cytospin from case of supressor T. PLL. $\times 800$.

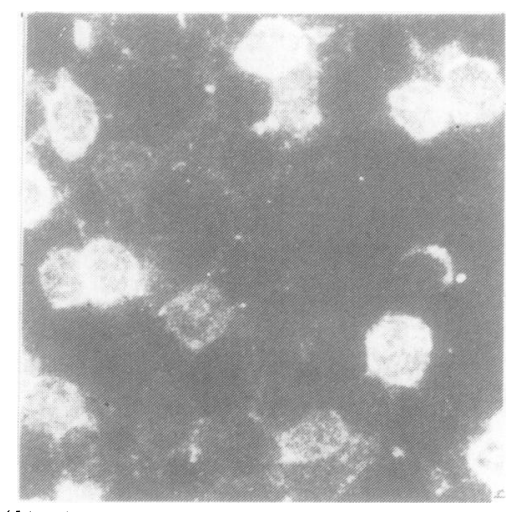

(b) OKT8 reacted imprint from diffuse lymphocytic lymphoma. $\times 800$.

We wish to thank Dr Margaret Haire and Dr S McMillan, Immunology Laboratories, Belfast City Hospital, for the use of the Leitz Ortholux I and for advice on numerous occasions. We also wish to thank Mr G Bradley and Mr T Welsh, Department of Medical Illustrations, Belfast City Hospital, for their expert photographic assistance and Mrs Deirdre Glen for typing the manuscript.

$$
\begin{array}{r}
\text { GERALDINE M MARKEY } \\
\text { HD ALEXANDER } \\
\text { TCM MORRIS } \\
\text { JH ROBERTSON } \\
\text { Department of Haematology, } \\
\text { Belfast City Hospital, } \\
\text { Lisburn Road, } \\
\text { Belfast BT97AD }
\end{array}
$$

\section{Faecal carriage of group B streptococci}

The results of a study conducted at this laboratory show that, contrary to the findings of Islam and Thomas, ${ }^{1}$ not only type II, but a wide range of serotypes ot group B streptococci (GBS) can be isolate $\bar{\phi}$ from adult faeces. These include types I anct. III which are the serotypes most commonl implicated in neonatal infection.

Routine faecal samples (175) wer studied. The first 94 specimens wer homogenised in glycerol broth and stored $-20^{\circ} \mathrm{C}$ for up to three months, while the res were dealt with immediately. A faecat suspension was made of $1 \mathrm{~g}$ of stool in $9 \mathrm{mfp}$ of glycerol broth or Ringer's solutio $\vec{D}$ (1/10). Two further tenfold dilutions were made in Ringer's solution (1/100) and $1 / 1000)$ and $200 \mu \mathrm{l}$ volumes of these serves as inocula for surface viable counts. Tw media were used: Islam's starch serum agarç and blood agar (Columbia agar base $+5 \%$ horse blood), both made selective by the addition of nalidixic acid $7.5 \mathrm{mg} / \mathrm{ho}$ polymyxin B $17000 \mathrm{U} / 1$ and neomycin $2 \cdot 125$ $\mathrm{mg} / \mathrm{l}$ (Oxoid Streptococcus Selectivg Supplement). In addition $1 \mathrm{ml}$ of the initiaج faecal suspension was inoculated into Todd Hewitt Broth (BBL) containing the sams antibiotic supplement, for enrichmen culture, and after overnight incubation $37^{\circ} \mathrm{C}$ this was subcultured on to the sams media. All plates were incubated overnight anaerobically at $37^{\circ} \mathrm{C}$ using the Gas 8 a system (BBL). Orange colonies on $\Phi_{h}^{\infty}$ Islam's medium and $\beta$-haemolytic colomes on blood agar were serogrouped coagglutination with the Phadebact systent (Pharmacia). All isolates were confirmed 9 GBS and serotyped at the Streptococcus Reference Unit, Colindale.

Out of a total of $17 \mathrm{GBS}$ isolated, 16 wer detected by enrichment as compared to onl 10 by direct culture. Viable counts in these 10 samples were in the range $4 \times 10^{3} / \mathrm{g}$ to 2 . $\times 10^{\circ} / \mathrm{g}$. Seven specimens however, had counts of $<10^{5} / \mathrm{g}$. The quantitative technique could not detect counts below 5 \% $10^{2} / \mathrm{g}$ which suggests that in the seve carriers detected by enrichment alon viable counts were below this level. The overall isolation rate of $9 \cdot 7 \%$ (Table 1) is comparable with previous studies: Islarf and Thomas $(4 \%)$, and Easmon et at $(6 \%)$, although there was a much highe? isolation rate from fresh samples $(16 \%)$ as compared to frozen ones $(4.3 \%)$. The numbers involved were too small forv statistical significance, but it is possible tha freezing may have reduced the recoverf rate of GBS, especially as viable counts tended to be low.

A wide range of serotypes were detecte (Table 2). Only two out of 15 isolates from adult faeces were type II strains, whereas 100 were either type I or III. The only othe $\bar{D}$ 
Table 1 Isolation rate of group B streptococcus from faeces

\begin{tabular}{llcl}
\hline Source & \multicolumn{2}{l}{ No positive/No examined $(\%)$} & \\
\cline { 2 - 4 } & Total specimens & Fresh specimens & Frozen specimens \\
\hline Males & $11 / 108(10 \cdot 2)$ & $8 / 48(16 \cdot 7)$ & $3 / 60(5)$ \\
Females & $6 / 67(9)$ & $5 / 33(15 \cdot 2)$ & $1 / 34(2 \cdot 9)$ \\
Total & $17 / 175(9 \cdot 7)$ & $13 / 81(16)$ & $4 / 49(4 \cdot 3)$ \\
\hline
\end{tabular}

Table 2 Distribution of group B streptococcal serotypes in faecal isolates

\begin{tabular}{lclllllllll}
\hline No of faecal carriers & \multicolumn{9}{l}{ Serotype distributions } \\
\cline { 2 - 9 } & & $I a$ & $I b$ & Ic-protein & II & II/Ic-protein & III & $X$ & $N T$ \\
\hline Adult female & 5 & 1 & 1 & 0 & 1 & 0 & 1 & 1 & 0 \\
Female $<16$ yr & 1 & 1 & 0 & 0 & 0 & 0 & 0 & 0 & 0 \\
Adult male & 10 & 0 & 0 & 4 & 0 & 1 & 3 & 1 & 1 \\
Male $<16$ yr & 1 & 1 & 0 & 0 & 0 & 0 & 0 & 0 & 0 \\
Total & 17 & 3 & 1 & 4 & 1 & 1 & 4 & 2 & 1 \\
\hline
\end{tabular}

report of GBS serotypes in faecal samples is that of Islam and Thomas ${ }^{1}$ who detected four type II strains in their series and suggested that type II may be the only resident gut flora in adults. Type II is an uncommon cause of serious neonatal infection, but serotypes I and III are much more frequently implicated (unpublished, PHLS Commun Dis Rep).

The isolation rate of GBS from both rectal and perianal swabs is much higher than from faeces. ${ }^{3}$ It may be that carriage is mainly limited to the perianal skin, which could contaminate rectal swabs, ${ }^{\prime}$ or alternatively, the rectum and anal canal may also be colonised. ${ }^{3}$ If the latter is true, it is surprising that faeces are not more often contaminated. In either case, it is impossible to be certain that GBS are gut commensals without examining stool specimens collected in such a way as to avoid contamination-for example, by sigmoidoscopy. Further studies are required.

CJ NOBLE Maidstone Public Health Laboratory, Preston Hall Hospital, Maidstone, Kent ME20 7NH

\section{References}

' Islam AKMS, Thomas E. Faecal carriage of group B streptococci. J Clin Pathol 1980;33:1006-8.

2 Islam AKMS. Rapid recognition of group B streptococci. Lancet 1977; ;:256-7.

${ }^{3}$ Easmon CSF, Tanna A, Munday P, Dawson S. Group B streptococci-gastrointestinal organisms? J Clin Pathol 1981;34:921-3.

\section{An evaluation of API-20 STREP and isolation of Streptococcus milleri}

The API-20 STREP system has been under evaluation in this laboratory for several months, and our results largely agree with those reported by Tillotson. ${ }^{1}$ The system is quick and reliable.

My particular interest has been infections due to Streptococcus milleri, and I can confirm that the API-20 STREP system enables the rapid identification of this organism. The Table shows the 15 isolations made from clinically significant lesions in a four-month period, in Glasgow Royal Infirmary. In 14 cases, Strep milleri was grown in pure culture or as the predominant organism from a purulent lesion, and the remaining isolate was from a blood culture, though not associated with endocarditis. Peritoneal and pelvic sepsis accounted for most of our isolates. There were no cases of brain abscess because such patients are not treated in Glasgow Royal Infirmary.

Rapid diagnosis is important, and, since the organism responds readily to penicillin, prompt adequate antibiotic treatment together with surgical drainage (where appropriate) can achieve an excellent clinical response. Untreated, the organism is responsible for considerable morbidity associated with failure of healing of surgical wounds.

\section{Isolations from significant lesions}

\begin{tabular}{|c|c|c|}
\hline Site/lesion & $\begin{array}{l}\text { No of } \\
\text { isolates }\end{array}$ & Comments \\
\hline Peritonitis & 5 & $\begin{array}{l}4 \text { post-op bowel surgery } \\
1 \text { appendicitis }\end{array}$ \\
\hline Pelvic sepsis & 4 & $\begin{array}{l}3 \text { post-hysterectomy } \\
1 \text { pelvic inflammatory disease }\end{array}$ \\
\hline $\begin{array}{l}\text { Pancreatic pseudocyst } \\
\text { Head and neck }\end{array}$ & $\begin{array}{l}1 \\
2\end{array}$ & $\begin{array}{l}\text { drainage fluid } \\
1 \text { post-op skin flap-reconstruction } \\
1 \text { spontaneous abscess }\end{array}$ \\
\hline
\end{tabular}

Empyema of pleura

Skin ulcer

Blood culture
In my hands, the API-20 STREP system is of real value in the busy routine diagnostic $\stackrel{\overrightarrow{2}}{\overrightarrow{2}}$ laboratory as a rapid and reliable method of 으․ identifying streptococcal species; it is particularly useful with the difficult $\stackrel{\oplus}{\longrightarrow}$ "indifferent" streptococci, such as Strep 음 milleri.

MORAG I BROWN Department of Bacteriology, Royal Infirmary, Glasgow G4 OSF क

\section{Reference}

' Tillotson GS. An evaluation of the API-20 STREP system. J Clin Pathol 1982;35:468-72.

Quality control terminology and some practical implications

The International Federation of Clinical Chemistry's (IFCC) approved recommendations on general principles and

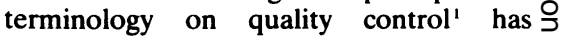
resolved several outstanding issues and $\rightarrow$ significant among these appears to be the $Z$ affirmation that the negative forms of the terms accuracy and precision should be used to describe the quantification of these parameters.

Though the measurement of imprecisiog $\vec{C}$ never posed a problem, the generaty accepted definition of accuracy-that agreement of results with the true value $\frac{0}{5}$ and the premise that the true value was an unknowable entity, ${ }^{23}$ have resisted efforts $\bar{\partial}$ at quantifying it directly. Recovery experiments hence became the generally $\mathbb{D}$ acknowledged means of assessing inaccuracy and the IFCC has accepted this.

Whitehead ${ }^{4}$ circumvented the rigidity of the aforementioned definition of accuracy by introducing a broader one-namely, the? relationship of a set of results to the correct value, where the correct value is the best? estimate of a quantity for a particular $\frac{5}{3}$ material using a defined analytical technique. As values can vary widely depending $\delta$ on the method used, this definition runs $₹$

bacteraemia after bowel surgery 